\title{
A Educação Paraibana da Colônia a Nossos Dias: uma Abordagem Histórica
}

\author{
José Octávio de Arruda Mello ${ }^{1}$ \\ UNIPÊ e UEPB
}

\begin{abstract}
Resumo
O artigo apresenta o contexto histórico da evolução da educação e do sistema educacional na Paraíba, um dos estados brasileiros. Os temas considerados são: escolas profissionalizantes; perspectivas teóricas; escolas históricas; ciclos históricos e progressos educacionais.

Palavras chave: Paraíba, história, educação, história da educação.
\end{abstract}

\section{Education in Paraíba from Colony Until to Day: one historical review}

\section{Summary}

The paper presents the historical context of the evolution of the education and of the educational system in Paraíba, one of the Brazilian States. The issues considered are: professional schools; theoretical perspectives; historical schools; historical cycles and educational advances.

Key words: Paraíba, history, education, history of education.

\section{O Contexto da Educação Paraibana}

Nesta tarde, acabamos de assistir ao documentário cinematográfico Parahyba, especialmente preparado pela dupla Machado Bittencourt / Alex Santos, para o IV Centenário do Estado, em 1985. Nele podemos perceber ampla evolução histórica da Paraíba, decomposta em períodos que nos trazem da conquista e colonização do século XVI às invasões holandesas do XVII, penetração territorial dos XVII e XVIII, rebeliões liberais, abolicionismo e republicanismo do século XIX, até o atual século XX. Neste, o vídeo ressalta além do impulso algodoeiro, responsável pela ferrovia e "surto de industrialização episódico de Campina Grande", a República dos Coronéis, sua contenção pelos Governo João Pessoa e Revolução de 30, e enfim, astutas sociais, secas e inundações de nossos dias, como contraponto para involução e crise que saltam à vista.

É dentro desse quadro que devemos situar a educação paraibana.

Como não havia lugar para ela em estrutura estamental regida pelo lucro e a mercancia, a transmissão do conhecimento dos primeiros tempos ficou a cargo das ordens religiosas que para cá se transportavam. Essa a função de franciscanos, jesuítas, beneditinos e carmelitas, responsáveis pelos aldeamentos da catequese. A esses também ficamos devendo templos religiosos de inspiração barroca e as mais recuadas formas de organização social.

As chamadas missões, então constituídas, representaram aparelhos ideológicos, ou seja, mecanismos de submissão da indiada para neutralização de sua rebeldia e submissão dos valores aos padrões do conquistador. Graças a isso é que, nas palavras de um historiador, "o terço do missionário seguiu sempre o trabuco do conquistador" (Mello, 1997).

Entre as missões religiosas dos primeiros séculos, se algumas se localizavam no litoral, em

\footnotetext{
${ }^{1}$ Endereço: A v. Senador Rui Carneiro, 425, CEP: 58.032- IO 1. João Pessoa - Paraíba - Brasil.
} 
Jacoca, Taquara, Guia, Almagre, Praia, Jaguaribe e Mangue, outras, mais para o interior, representaram pontos de apoio para a conquista da terra. Tal a do Pilar, onde capuchinho italiano, natural de cidade de Modena, albergou os Cariris e assegurou base para os entradistas que se deslocaram ao longo do rio Parahyba. A futura cidade de Pilar, imortalizada nos romances de José Lins do Rêgo, resultaria dessas peripécias (Mello, 1983).

De acordo com Gilberto Freyre, dois principais modelos pedagógicos - o franciscano e o jesuítico - competiram na sociedade colonial brasileira dos primeiros séculos. O primeiro, que buscava a valorização do trabalho pelo incremento das atividades manuais, defrontou-se com o jesuítico, de Ratio Studiorum, fundado no latim.

A desvalorização do trabalho manual acarretado pela escravidão fez com que prevalecesse a educação discursiva da repetição mnemônica.

Fundada no latim essa prática pedagógica reservava-se às camadas mais altas da população. Enquanto a grande massa permanecia analfabeta, só índios mais próximos do litoral eram aculturados, por intermédio do teatro e da música barroca. Introduzidos pelos padres jesuítas em suas missões, ambos, tal e qual a religião com que se articulavam, faziam as vezes de instrumentos de aculturação e controle social dos nativos.

\section{Problemas do Ensino Profissionalizante}

Nesse contexto, a educação paraibana refletiu a estrutura de classes de sua base econômicosocial.

Seus índices bastante precários, asseguravam, historicamente, a educação de reduzidíssima camada, absolutamente avessa ao trabalho manual.

A educação neste inspirada e destinada à formação de mão-de-obra limitou-se a esparsas experiências. No século passado, alguns missionários como padre Ibiapina, procuraram incentivar atividades manuais de serralharia e carpintaria para homens e corte e costura e bordado para as mulheres, nos limites de suas casas de caridade.

Algumas escolas religiosas para mulheres, já neste século, assim como orfanatos e asilos, de inspiração confessional, seguiram esta linha de ação que, todavia, não se cristalizou na Paraíba. Foi junto à Escola Doméstica de Natal, no Rio Grande do Norte, favorecida pelas idéias do escritor Henrique Castriciano, que a experiência melhor se consolidou conforme Albuquerque (s/d).

Mesmo assim, algumas tentativas de renovação educacional tiveram lugar na Paraíba do século XX.

Nos primeiros decênios, a supressão do trabalho escravo e a evolução do comércio fomentado pela urbanização geraram a Academia de Comércio da Paraíba, fundada em 1922 e sediada na capital. Na década anterior, a Escola de Aprendizes Artífices (1912) começou a funcionar junto ao Quartel da Polícia Militar (Weber, 1997). Esta Escola seguia modelo suíço importado pelo Presidente Nilo Peçnha.

Com a Revolução de 30 e as teses de chamada Escola Nova, aqui representada pelos educadores José Baptista de Melo, Batista Leite, João Vinagre e Sizenando Costa, além de, posteriormente, o diretor da Instrução Pública Calheiros Bonfim, sobreviveram os SESC, SENAC e SESI. Se o primeiro interiorizou-se, com extensão a cidades como Guarabira e Souza, foi o último 
que se sobressaiu, mediante a formação de quadros profissionais em Campina Grande e Rio Tinto, sob a liderança dos executivos Stênio Lopes e Rogê Maciel Pinheiro.

Convertida em Escola Industrial e, posterim'mente, Escola Técnica Federal da Paraíba, a antiga Escola de Artífices evoluiu para, até, funcionamento de unidade de apoio, em Cajazeiras, no alto sertão paraibano, a partir da década de noventa. Alguns de seus programas buscaram associar o empresariado à formação de mão-de-obra para a indústria. Buscou, nos anos setentas, esta parceria através do Centro de Integração Escola/Empresa, coordenado pelo sociólogo Aníbal Peixoto Filho.

Se na área estadual, os chamados Ginásios Polivalentes e Orientados para o Trabalho ficaram muito aquém da intenção dos planejadores do regime militar dos anos setentas, a Universidade ofereceu melhores espaços à chamada educação prática.

Isso tanto se verificou em João Pessoa, com os cursos de Engenharia e Arquitetura, como embriões do atual Centro de Tecnologia (CT), da Universidade Federal, hoje dotados de excelentes mestrados, como em Campina Grande onde a Escola Politécnica despontou na década de cinqüenta. Dessa última, derivou a liderança técnico-pedagógica do executivo Edvaldo do Ó a quem se deve a atual VEPB, com alguns mestrados na área médico-científica e efetiva ação no chamado compartimento da Borborema. Em Campina, o segmento tecnológico tem recebido a contribuição da UFPB.

Na microrregião do brejo, o ensino agrotécnico avançou com a Escola Agrotécnica Vidal de Negreiros, na década de vinte, em Bananeiras, preliminarmente dirigida pelo agrônomo José Augusto Trindade, pai do atual Reitor do UNIPÊ, cônego Marcos Trindade, e a escola de Agronomia do Nordeste, na década seguinte, em Areia. Modernamente, ambas constituem dinâmicos Centros de Ensino e Pesquisa da UFPB. Com isso, acusaram melhor destino que o antigo Patronato Agrícola de Pindobal, em Mamanguape, no litoral. Este último, não definiu suas finalidades após as iniciativas do professor Adailton Coelho Costa, nos anos oitentas. Em Lagoa Seca, junto a Campina Grande, o curso de Técnicas Agrícolas da VEPB encontra-se prestes a fechar. Esse não é o caso da Escola Agrícola de Catolé do Rocha, no sertão, exitosamente mantida pela VEPB.

\section{Privativismo, naturalismo e humanismo}

Uma das características históricas da educação paraibana, entrosada com a brasileira, consistiu em seu caráter privado.

Com efeito, deslocada para o interior das famílias, ela registrou a predominância do chamado mestre-escola (Menezes,1982). Alguns desses passaram à História, como os latinistas Joaquim da Silva, em Areia, e Luiz Aprígio, em Mamanguape e ainda Demétrio Toledo, no Pilar, DI'. Brandão, em São João do Cariri, Anésio Leão em Campina Grande e Patos, Rafael Corrêa de Oliveira em Pombal e Amaro Gomes Coutinho e Severo Rodrigues, em Santa Rita. A categoria, a que hoje se retoma com o chamado reforço escolar, ganhou nova dimensão em as Escolas Normais de Curso Pedagógico, a partir dos anos vintes.

Foi então a época das professoras primárias que se sobressaíram como Hortence Peixe, Adamantina Neves. Tércia Bonavides e Adélia de França, em João Pessoa, Maria das Neves Pires e Eulina Serrão, em Santa Rita, Adalgisa Amorim, Doziá Quirino e Ilsa Luna, em Campina Grande, 
Maria Medeiros, em Santa Luzia, irmãs Eudócia Queiroz Fernandes e Nelita Nóbrega Queiroz, em Patos, Aracy e Ernestina Leite, no Piancó, Elzira Matos, em Souza.

O caráter privativista da formação social brasileira, ressaltado por Nestor Duarte, fez com que a primeira cadeira pública, e de Latim, somente fosse criada em 1766, com provimento em 1783. Essa a razão pela qual "mantido na obscuridade, o povo paraibano aprendeu a ler sem escolas" (Mello, 1997).

Quando da criação da primeira cadeira escolar mantida pelo govel11o, os jesuítas haviam sido expulsos do Brasil, o que levou o Marquês de Pombal àquela providência. Um pouco mais tarde, em 1822, funcionavam escolas de primeiras letras na Paraíba, nas vilas de Conde, Alhandra, Monte Mór, São Miguel, Pilar, Brejo de Areia, Nova Rainha (Campina Grande), São João, Pombal e Souza Mello (1956).

Bem mais importantes que esse arremedo de estrutura educacional, fizeram-se as experiências pedagógicas do naturalista paraibano Arruda Câmara, na qualidade de médico formado em Montpellier, na França. Ao pesquisar a fauna e flora nordestinas, Câmara, de quem hoje se contesta o liberalismo maçônico, lançou as bases do naturalismo pedagógico, irmão gêmeo do naturalismo filosófico da Revolução Francesa.

Na outra vertente do chamado humanismo, quem mais se distinguiu foi o padre Inácio de Souza Rolim, responsável pela tradição pedagógica de Cajazeiras, no alto sertão paraibano. Sua escola localizava-se em fazenda da freguesia e deslocou-se para Inhamuns, no Ceará, por ocasião da epidemia de cólera, em 1856. O caráter itinerante das escolas da época positivou-se, igualmente, na região noroeste do Estado, com o educador Antonio Gomes de Arruda Barreto. Também político, advogado e jornalista, deslocou seu colégio Sete de Setembro um dos únicos do sertão, na passagem do século, de Brejo do Cruz para Mossoró e Martins, no Rio Grande do Norte, antes de retomar a Catolé do Rocha, na Paraíba.

Tanto Rolim quanto Barreto constituíram expressões da escola doméstica, assim rotulada por Rafael de Menezes, como a que, a certa altura, ofereceu o tom da educação paraibana.

\section{O Liceu e a institucionalização do ensino}

A institucionalização da educação paraibana data de 1836, com a criação do Liceu Paraibano, inicialmente localizado no prédio do antigo Colégio dos Jesuítas, fundado em 1745 pelo sacerdote italiano Gabriel Malagrida que padeceria nos cárceres da Inquisição, em Lisboa. Esse estabelecimento, mantido pela Companhia de Jesus, funcionava como seminário que, dotado de aulas de Latim e Humanidades, funcionou como primeiro estabelecimento de ensino geral (Mello, 1956).

Funcionando nos moldes do Colégio Pedro 11, do Rio de Janeiro, o Liceu Paraibano conheceu duas sedes que ainda perduram antigo Colégio dos Jesuítas, na atual praça João Pessoa, vizinho ao Palácio da Redenção, e a de nossos dias, instalada por Argemiro de Figueiredo, na avenida Getúlio Vargas, em 1939.

Esta última, inicialmente repal1ida com o Instituto de Educação cujo curso Normal representou o núcleo da Escola de Professores, consolidou o prestígio de estabelecimento que, pelos anos vintes, fomentou o modernismo paraibano e o dinamismo cultural da sociedade (Mello, 1979). 
Por essa época, o Liceu Paraibano, a Escola Normal e o jornal A União, todos sediados na capital, constituíram o tripé da cultura paraibana, cooptada pelo Governo. Como esse tripé se complementasse com o Seminário Arquidiocesano e o Colégio Diocesano Pio X, ambos de inspiração confessional, surgiu o entendimento de que o elemento religioso nele predominava.

Nem tanto. Assim, a uma corrente de professores, sacerdotes, escritores, oradores do melhor nível correspondeu plêiade de mestres recrutados à sociedade civil. Estes eram, igualmente, professores do Liceu e escola Normal, jornalistas do A União, e integrantes do Instituto Histórico e Geográfico Paraibano, cuja criação em 1905, ocorreu nos salões do Liceu Paraibano, além de membros da Maçonaria, incompatibilizada com a Igreja. As polêmicas culturais das décadas de vinte e trinta, pela imprensa paraibana e pernambucana, refletiu o entrechoque dessas duas vertentes do ensino da Paraíba (Mello, 1979). Uma era ultramontana e a outra agnóstica, derivada da chamada Escola do Recife, albergada na Faculdade de Direito dessa cidade.

\section{Do Império à República, um recuo no tempo}

Bastante ressaltados pela tradição e estudos como o de José Rafael Menezes (Menezes, 1983), o Liceu fez-se mais eficiente como formador de quadros para a alta administração e cultura estaduais que como instrumento de democratização do ensino e incorporação das massas ao processo educativo da Paraíba.

Esse, em fenômeno de que não se podia cogitar no século XX onde a base agropastoril da economia não assegurava senão educação elitizada e de reduzidos quantitativos.

As estratégias coligadas pelo sociólogo Cláudio José Lopes Rodrigues, são a esse respeito, sintomáticas. Em 1838, o número de alunos do Liceu era de 120, cifra que variava para 66 em 1844, 78 em 1852, 93 em 1860, 123 em 1866 e 96 em 1877. Rodrigues(1980).

As mulheres não faziam parte desse quantitativo, visto que a primeira escola para o sexo feminino somente surgiria com o Colégio das Neves, de irmãs francesas importadas pelo presidente Beaurepaire Rohan, em 1858. Dois anos depois, invocando falta de recursos, o presidente da província de Luiz da Silva Nunes a fechava.

Nas palavras de abalisado pesquisador da educação paraibana, José Batista de Melo, as scolas profissionais da época do Império efêmeras e pouco operativas - reservavam-se às crianças desvalidas - eterno cacoete do elitismo. Quanto às demais, nada ensinavam a julgar pelo diálogo mantido por um ex-aluno com o viajante Daniel P. Kidder, em 1840 (Kidder, 1943).

\section{Da herança do Império à Revolução de 30}

Conforme Melo (1956), em Evolução do Ensino na, "o Império nos seus sessenta e sete anos havia nos dado 67 escolas primárias que, somadas com as doze vindas da Colônia, perfaziam um total de sessenta e nove. Tínhamos, segundo a estatística da época, 2.284 alunos nas aulas públicas, 225 no Liceu Paraibano e 23 no Externato Normal, além de algumas dezenas de estudantes nos cursos de Latim que funcionavam em Areia, Mamanguape e Souza".

Como por volta de 1856, a província já contava com 300.000 habitantes dos quais 30.000 na 
capital somente foi inaugurado em 1917, o que em Campina Grande somente ocorreu cinco anos depois. Nessa mesma cidade, apesar do crescimento verificado com a chegada do trem em 1907, a educação continuou impulsionada por mestres-escolas como Clementino Procópio. A este sucederam Anésio Leão e Alfredo Dantas, o último dos quais, militar, tornou-se responsável, na década de trinta, pelo ginásio que lhe ganhou o nome.

Dentro desse quadro, a estrutura educacional paraibana somente merece esse nome, a partir da Interventoria Antenor Navarro, entre 1930 e 32. Neutralizando a influência do clero e projetando os reflexos revolucionários pré-trinta, Navarro avocou ao poder público ensino primário dotado do controle de inspetores, caixas escolares e novos serviços como conto, coral e educação física. Dez grandes grupos escolares que ainda hoje prestam excelentes serviços foram disseminados pelas principais cidades do Estado.

\section{Colégios religiosos, Fundações e Ensino Público}

A partir da segunda metade dos anos trintas, várias ordens de freiras brasileiras e estrangeiras principiaram a instalar colégios para moças em cidades como Guarabira, Alagoa Grande, Bananeiras, Princesa Isabel, Catolé do Rocha, Areia e Itaporanga, no esquema de internatos.

Com o ensino religioso sertanejo animado pelo bispo de Cajazeiras, Dom João da Mata Amaral, a insistência ainda era privada, o que prosseguiu com os ginásios comerciais da Campanha Nacional de Escolas da Comunidade (CNEC) e Fundação Padre Ibiapina dos educadores Felipe Tiago Gomes e Afonso Pereira.

Nesses termos, a presença do Estado na educação paraibana somente se tornou efetiva com os anos cinqüentas.

A Universidade Estadual da Paraíba, preconizada por José Américo, era então uma realidade, cabendo a esse mesmo governante inaugurar o primeiro Colégio Estadual de fora da Capital. Era o Colégio Estadual do bairro da Prata, de Campina Grande, datado de 1953, sobre estrutura física iniciada pelo Governador Oswaldo Trigueiro (1947 - 1950).

Com o populismo gondinista, de 1958 a 60, os colégios estaduais, transportados a Sapé pelo Governador Flávio Ribeiro, em 1958, ganharam os bairros de João Pessoa, e a seguir os de Campina Grande. Com Gondim novamente no governo, de 1961 e 1966, tais estabelecimentos foram estendidos ao interior, para suprirem lacuna existente em municípios como Guarabira e Pombal que, na década de cinqüenta, contavam apenas com modestíssimas escolas de curso comercial de primeiro grau. Com José Medeiros Vieira na Secretaria de Educação e Cultura, o governador João Agripino dotou aqueles educandários de condignas instalações.

\section{Analfabetismo, teleducação e professorado leigo}

Essa expressão educacional paraibana, que apontava mais para o crescimento que para o desenvolvimento da educação, fazia-se de forma desordenada. Tanto assim que, na base, persistia o grave problema do analfabetismo, agravado pelo latifúndio que as nascentes Ligas Camponesas (1958 - 1964) desafiavam. 
A consciência do analfabetismo dominou a sociedade paraibana em momento de agudização das lutas sociais, de modo que foi a nível ideológico que se processou seu enfrentamento. Enquanto pela centro-esquerda avultava o SIREPA, como responsável pela primeira experiência de educação pelo rádio, na Paraíba, a extrema esquerda organizou a CEPLAR para ousada tentativa conscientizadora de alfabetização, baseada no método Paulo Freire. Com o movimento de 64 e a supressão da CEPLAR, prevaleceu a Cruzada ABC, de inspiração evangélica e financiamento norte-americano (Scocuglia, 1997).

Do SIREPA saíram os quadros da experiência estadual do Projeto Minerva que, com base na rádio e posteriormente na televisão, encaminhou grandes massas para os exames supletivos, reestruturados pelo secretário José Carlos Freitas, durante a administração Ernany Satiro (19711975). Enquanto a educação à distância da Paraíba era considerada modelar, o mesmo não se verificou com o MOBRAL, destinado a conter o analfabetismo. Por toda parte, esse teve no desperdício de recursos e material, além da politicagem, a principal característica. O autor coordenou o Projeto Minerva de 1971 a 1977, extraindo completo relatório da experiência, incorporado aos arquivos do Grupo José Honório Rodrigues. Quanto ao MOBRAL são inúmeras as referências desfavoráveis constantes das Mensagens Governamentais e Relatórios da Secretaria de Educação, na década de setenta.

Ao lado do analfabetismo, que o MOBRAL não deteve, outro problema acusado pela educação paraibana foi o do chamado professorado leigo, isto é, sem habilitação adequada. Para equacioná-lo, os governos federal, estadual e municipal conjugaram-se no chamado Projeto Logos cujos resultados revelaram-se aquém dos esperados. A Universidade contribuiu com Mestrado de Educação de Adultos de boa qualidade, o qual todavia, formou mais especialistas de nível que pessoal capaz de atuar junto à raiz do problema.

\section{Dos Centros de Educação à grande crise}

Com o populismo e a expansão educacional dos anos 50/60, o sistema pedagógico paraibano ganhou três núcleos de capacitação profissional do melhor nível. Tais os Centros de Treinamento de Professores de Sapé, Alagoa Grande e Souza que, mesmo a elevados custos, formaram quadros médios de boa qualidade e asseguraram apoio a sem número de programas e projetos pedagógicos.

Entre 1960 e 70, os colégios estaduais do interior, todos inspirados no modelo do Liceu, acusaram bom rendimento e firmaram favoráveis perspectivas para a educação paraibana. Em cidades como Patos, Cajazeiras, Alagoa Grande, Bananeiras, Princesa Isabel, Itaporanga e Monteiro, eles prolongaram os antigos estabelecimentos religiosos, com aproveitamento até de seus quadros administrativos e docentes. O de Cajazeiras, seguindo o modelo de muitas cidades brasileiras, converteu-se em Faculdade de Filosofia confessional, como embrião do campus da Universidade Federal Iglésias (1985).

Nesse contexto, a grande crise da educação paraibana sobreveio com os anos oitentas em que, acompanhando o declínio da economia e a virtual desintegração do Estado, que passou a pagar baixíssimos salários, motivando sucessivas greves como resposta do professorado, o sistema pedagógico colapsou.

Os resultados vieram a seguir. Nos anos noventas, as estatísticas revelaram como analfabetos 
metade da população paraibana acima dos quinze anos. Nas escolas estaduais e municipais de primeira fase de primeiro grau, os índices de evasão e repetência revelaram-se dos mais altos do país. Em 1996, estatísticas do IPEA revelaram a Paraíba, entre os Estados brasileiros, em último lugar em esperança de vida, penúltimo em escolaridade e antepenúltimo em produto interno bruto per capita. Mello e Nóbrega (1998).

\section{Cartorialismo e qualidade universitária}

Não há dúvida de que o clientelismo contribuiu para esse estado de coisas.

Com efeito, a apropriação do sistema pedagógico paraibano pelas oligarquias significou anomalia que incidiu sobre setores como o do ensino Normal. Neste, das trinta e duas escolas existentes, raríssimas merecem este nome, até porque algumas estão localizadas em cidades que não comportam sequer boa escola de primeiro grau. Em Princesa Isabel, cada facção partidária montou uma escola normal e nenhuma presta. Como resultado, a classe média princesense envia filhas para o curso Normal de Patos, a mais de cento e cinqüenta quilômetros.

É óbvio que essas distorções podem ser equacionadas, mediante adequada vontade política.

Do ponto de vista técnico, uma das possibilidades de enfrentamento das anomalias pedagógicas da Paraíba reside na qualificação do pessoal preparado por suas três universidades.

Mais antiga de todas, a Federal possui excelente centros pedagógicos em João Pessoa e Cajazeiras, além dos campi em Areia, Bananeiras, Campina Grande, Patos e Souza.

A UEPB revela no CEDUC, do Bairro do Catolé, em Campina Grande, Departamento de Pedagogia que prima pela qualidade. Enfim, em João Pessoa, o UNIPÊ tem cuidado de aprimorar seu pessoal docente, discente e administrativo, em larga escala. Além disso, sob a inspiração da dupla Marcus Trindade - José Loureiro, é visível a disposição de voltar-se para a comunidade, através de agressivo programa cultural, além da ação de cursos como Pedagogia e Psicologia.

A Paraíba faz-se assim unidade federada de relevante brain-trust, mas o problema não reside aí, no alto, mas na base corroída pelo clientelismo.

Proclamo essas coisas não por desesperança, mas pela consciência de que devemos lutar contra elas.

Se os senhores puderem fazer algo por essas mudanças, a Paraíba agradece. Agradece em meu nome, mas agradece.

\section{Referências}

Albuquerque, J. G. (s/d) Henrique Castriciano. Seleta de Textos e Poesias. Natal: UFRN, s.d., passim. Iglésias, F. (1985). Momentos Democráticos na Trajetória Brasileira, in: Brasil. Sociedade Democrática, de Jaguaribe, Hélio et allia. Rio de Janeiro: José Olympio, 192.

Kidder, D. P. (1943). Reminiscências de viagens e permanência no Brasil. São Paulo: Livraria Martins, 114. Mello, 1. B. de (1956). Evolução do ensino na Paraiba. João Pessoa: Imprensa Oficial, 20.

Mello, J. O. de A. (1997). História da Paraiba-Lutas e Resisitências. 5 a ed. João Pessoa: Editora Univesitária, UFPB, 79

(1983). Geo-História e Formação de Cidades na Paraíba, in: José América e a Cultura Regional.

(1979). A Paraíba e a década de vinte, in: João Pessoa. a Paraíba e a Revolução de 30. 
Mello, 1. O. de A. e Nóbrega, E. (org.) (1998). Sociedade, Cultura e Governo da Paraíba do Tempo Presente, in: História da Paraíba em fascículos

Menezes, J. R. (1982). O mestre escola brasileiro. (1983). História do Lyceu Parahybano.

Rodrigues, C. J. L. (1980). Profissão: Professor Secundário (Estudo histórico-sociológico de uma categoria profissional).

Scocuglia, A. C. (1997). A História da Alfabetização Política na Paraibrasil dos Anos Sessenta. 